excellent home for middle-class patients with which $I$ am now associated at Wandsworth Common, known as Bolingbọke House.

CAsE 1.-Mirs. R__ a lady aged sixty, spare but healthy, who for years had at times experienced trouble with her bowels, necessitating the frequent recourse to medicine, came under my care with a distended, tender, and tympanitic abdomen, showing central coils of intestine in a marked manner, frequent vemiting of a bilious character (aggravated by food), and complete constipation of ten days' starding. Pulse normal, but feeble. Temperature subpormal. Urine scanty. A rectal examination gave no evidence of local trouble. The case was supposed to be one of stricture of the large bowel high up. Not feeling suffi. ciently sure of this diagnosis, I determined to wait before pxoceeding to operate, and ordered her to have her abdomen covered with a mixture of one drachm of the extract of belladonna and an ounce of glycerine, and to be fed by a 4.oz, nutrient enema, alternating with a nutrient meat suppository every four hours, and a teaspoonful of warm water by the mouth every half hour. Relief to pain and alleviation of all her symptoms soon followed this treatment, and on the fourth day-that is, on the fourteenth of her symptoms-some flatus passed. On the sixth day of treatment, or sixteenth of obstruction, some feculent matter of a grey colour came away. On the seventh day, after a small glycerine enema, a moderate motion was discharged, when food by the mouth was recommenced, and in another two weeks the symptoms had disappeared and the bowels gradually recovered their normal action.

CASE 2.-J. G__, a man aged thirty-two, came under my notice with abdominal syraptoms suggesting the thought that he had an intussusception. He had been ill four days and had been constipated for a week. Three days before I saw him lie took a dose of castor oil which caused vomiting, and this was soon followed by atraining and the passage of blood and mucus from the bowel, but no freces. Since then be had had abdominal pain of a somewhat paroxysmal character. When seen his abdomen was slightly distended and tender on the right side. No lump could be felt; nothing was to be felt on examination per anum. I ordered him to be kept warm in bed and to lie still. He was not to take any food by the mouth, only a teaspoonful of water every half hour, but to be fed by nutrient enemata (four ounce) alternating with a meat suppository every three hours. The first enema to have twenty drops of laudanum in it. During the next twenty-four hours he passed blood and mucus seven times, accompanied with tenesmus but no freces. The enemata were continued, but each one was to contain twenty drops of landanum. On the fourth day of treatment, but the eleventh of obstruction, a liquid motion with flatus was passed, with relief; on the fifth day the same relief; on the tenth day some solid motion came away, but with a blood-clot, and in three weeks his abdoninal symptoms had disappeared. I cannot but think that if any of the lines of routine treat ment to which $I$ have alluded had been applied to this case that a different result would have taken place. As it was, I left nature alone and siniply kept the machinery of life going by rectal alimentation, and checked peristalsis by opium.

CASE 3.-Anne B — a _ a nineteed, who for some weeks bad suffered from difficulty in obtaining relief from her bowels, after seven days' complete obstruction, was seized with abdominal pain, distension, and tenderness, with vomiting. These symptoms continued and increased in severity for four days, when she came under my care. Her abdomen was then very tense and tender. Nothing could be made out by palpation. She vomited everything she took, and even without food. Nothing had passed the anus for eleven days, not even flatus. There was no abnormal temperature and nothing could be felt in the rectum. I ordered her the belladonna externalapplication, as in the first case, and a nutrient 4-oz. enema of milk and egg, alternating with a meat suppository every three hours, and a teaspoon ful of fluid by the mouth every half hour to relieve thirst. On the second day the symptoms were improved, the abdo unen was less tense and painful, and vomiting had ceased. On the fourth day of treatment, or fifteenth of obstruc. tion, whe was still better, consequently a few ounces of thin liroth were allowed. On the fifth day of treatment and sixteenth day of obstruction the bowels acted, and continued to do so, when an enema was given to clear out the rectum of the solid motion which had passed down, and a rapid recovery ensued.
The results that followed the treatment which these cases illustrate were satisfactory, and I am induced to think they were better than any that would have followed the use of powerful purgatives, large enemata, or the abdominal taxis. The treatment, moreover, was simple, and, though expectant, it did no harm. Of such treatment we may reasonably say that it gives time in the only class of cases to which it is applicable-viz., those of a not urgent but doubtful nature-for the case to develop, and the surgeon to frame a more exact diagnosis; whilst it leaves nature every chance of making right, where this is possible, what may have been wrong in the abdominal machinery. Should the symptoms in any given instance fail to be speedily relieved by this treatment, more active measures can be resorted to as soon as a clearer working diagnosis has been made.

In some cases opium may be more freely given than these three cases indicate; but I hold that where belladonna as an external application arrests peristalsis and soothes pain opium is not needed. In many cases it is, however, most valuable; the form I like best is either the solid opium or the bimeconate of morphia. It should, however, al ways be given with caution. I prefer to employ it with belladonna as a suppository made with gelatine-half a grain of the extract of belladonna and half a grain or more of solid opium. Warm fomentations to a swollen abdomen often give comfort; when employed they should be placed over the glycerine and belladonna application already mentioned. In a case of obstructed bowel from a supposed band with mild symptoms I have known relief to follow the elevation of the pelvis on a firm pillow, so as to allow gravity to act towards the thorax; and I believe that with this treatment combined with starvation and the use of belladonna and opium, I have had cases of natural recovery. I claim no novelty in the treatment $I$ am advocating. I only want to enforce its value, and should indeed be pleased to know that it had superseded the routine practices to which I have drawn attention, and which have for too long occupied the field. The principle upon which it is based was first re commended by Sydenham ; it was reintroduced by Brinton, and more recently enforced by Thomas, with some modifications. It may be summed up as follows. The recumbent position with elevation of the pelvis, abstention from all food by the mouth, rectal alimentation, the external use of belladonna and glycerine, and the administration of belladonna and opium to check peristalsis and soothe pain.

\section{ON THE ACTION OF KOCH'S REMEDY UPON INTERNAL ORGANS IN TUBERCULOSIS. ${ }^{\text {T }}$}

\section{BY PROFESSOR R. VIRCHOW.}

LIMITING his remarks to facts determined by anatomical investigation, Professor Virchow said that from the time at which the practice commenced until the end of December he had examined post mortem twenty-one cases in which during life injections of Koch's fluid had been practised, and to these might be added some six or seven more examined during the present year. [A large number also have been examined by his assistants in other hospitals and elsewhere, and had yielded important facts. ]

There is an obvious difference between those cases in which the changes taking place in superficial parts can be observed clinically, and those where the internal organs are affected to an extent difficult to estimate by the most careful clinical investigation; and it is of interest to contrast the latter with the former. Of the twenty-one cases referred to, sixteen were cases of phthisis in the limited sense-i.e., in which the lungs were especially involved. The remaining five cases comprised:(1) A well-marked case of tuberculosis of bones and joints; (2) a case presenting the rare concurrence of cancer of the pancreas with small smooth-walled cavities in lung and apical induration; (3) an empyema in a puerperal case, which would probably have proved fatal apart from the injections; (4) pernicious anæmia, with very limited old lesions in lungs and tuberculous pleurisy; and (5) a case of arachnitis tuber culosa. In the remaining sixteen, strictly pulmonary cases, all showed more or less extensive phthisical ulceration.

Abstract of remarks made during the debate on Dr. B. Fraenkel paper at the Berlin Mledical society, Jan. 7th, 1891. (From full tex given in the "Berliner Klinische Wochenschrift," No. 2, 1891. 
The LaNCET,] PROFESSOR R. VIRCHOW : KOCh'S REMEDY IN TUBERCULOSIS. [.J AN. 17, 1891.131

Reserving for another opportunity a detailed statement of these cases, Professor Virchow proceeded to make some general remarks on the experience derived from them. Just as observation of external parts had shown that the remedy acts as a severe irritant, exciting redness and swelling, so the same effects had been well seph in the internal parts. He showed a preparation from case of arachnitis tuberculosa in Henoch's clinic, in which there were also some old caseo-pneumonic areas in the lungs (the probable focusjof the neningeal metastasis), together with recent inflammatory changes. After four injections, amounting in all to two milligrammes, the last being sixteen hours before death, the patient (a boy two years and a half old) died. Professor Virchow did not remember ever having seen so "colossal" a hyperamia of the pia mater, and even of the brain itself. The pia matral vessels were extremely distended, and the brain tissue of a dull reddish tint. In this, the only case of the kind in the series, he personally examined the tubercles in the arachnoid, but could detect no degenerative changes in them; they were well formed and of the ordinary character. Similar conditions of acute hyperamia and swelling $\rightarrow$ were also to be found in other internal organs. They, had often noted an unusual deep injection of the granulation layers of old pulmonary cavities; sometimes a hæmorrhagic infiltration of the walls, or evidence of recent hæmorrhage into the cavity. In a man thirty years of age, with an old rectal fistula and numerous tubercular ulcers in the colon, death followed upon hremoptysis from an old ulcerating focus; he had been injected seven times, the last occasion when the hremorrhage set in, being thirteen days before his death. But these visible changes were not confined to such marked hyperæmic swellings, which obviously might be very transient, for there was not the least doubt that actual inflammation, with active proliferation, occurred to a consilerable extent. This is well shown at the margins of ulcers and in the neighbouring lymphatic glands, especially the bronchial and mesenteric. The glands were most markedly swollen, that form of medullary swelling peculiar to acute irritation, and due to a rapid proliferation of the cells within the gland. This change is often associated with obvious lencocytosis, which may be assisted by the infiltration of white blood-corpuscles around the tubercle. Sometimes these inflammatory swellings are dangerous. Thus in the larynx, although the ulcers may become healthier, the neighbouring tissue enormously swells, and may produce a critical degree of stenosis. Sometimes the change may assume a phlegmonous type, comparable to what is seen in odema of the glottis and retro-pharyngeal abscess, as illustrated in a case seen this month (January). No doubt it is difficult to assert that any such inflammation is due to the injections, for there is no criterion for any differentiation; nor was he prepared to say precisely how this kind of inflammation may be recognised and distinguished from other inflammatory lesions arising in the course of phthisis. But in the lungs certainly there are lesions which are exceptionally peculiar.

Among the fatal cases of ulcerative phthisis the great majority showed widespread changes of recent date, mostly in the lungs, but also associated with pleurisy of very severe type, simple and tubercular, høemorrhagic and not rarely bilateral. The lung changes may be separated into two seemingly very different categories. The one corresponds to what is styled "caseous pneumonia," or anatomically, "caseous hepatisation." It might be thought very doubtful whether this change was in any way connected with the injections. Professor Virchow would himself have doubted this were it not that some of the case showed it in a special degree, and he exhibited a portion of lung which had undergone caseous hepatisation to an extent the like of which he had not seen for years. The lungs were large, their lower lobes, especially the right, as voluminous as in ordinary hepatisation; but the foci were so thickly massed as to leave hardly any parenchyma between them. It was like a piece of black sausage richly laden with fat, The non-caseous parts were blackish and sharply demarcated from the caseous. The man was thirty-threeyears old; he had had six injections, the last four weeks before death, and thein jections were suspended becauss of superven tion of continued fever and infiltration of thelowerlobes. This infiltration started just after the injections, for previously there were only signs of induration at one apex, where was afterwards found an old indurated focus. In other cases also, the condition of the lungs similarly differed from what is usually seen in phthisis; in fivo of the cases there were more or less large masses of caseous hepatisation, but not approaching the extent of the case related.

Another change, which is certainly inflammatory, is of a more diffinge character, although again not absolutely distinctive. The types of pneumonia liable to arise in the course of phthisis may be placed in three different categories. There are the caseous, the ordinary fibrinous, and the catarrhal, so-called smooth pneumonias-marked essentially by cell accumulations in the alveoli. One nuay see all these forms in a case of phthisis, but in not one of the injected cases was simple tibrinous pneumonia present." In fact, the "injection pneumonia" resembles the catarrhal type, but with certain differences. Catarrhal pneumonia, as ordinarily met with in phthisis, exhibits a moderately fluid collection in the alveoli, which can only be slightly expressed from them. Sometimes the contents are much more watery, like brine, and it way this which led Laennec to speak of gelatinous infiltration preceding tubercular inflitration. But the product in these cases is not gelatinous; it is rather watery and turbid; it might be called cloudy infiltration, and calls to mind a plategmonous condition. In some parts it is more opaque ; in parts it has a superficial likeness to caseation, but without its dry cha. racter, and there is no difficulty in distinguishing the two. The catarrhal phlegmonous condition is softer, moister, and laxer, as in a specimen shown, where around large ulcerating cavities in the apex of lower lobes were caseous masses and catarrhal inflammation. Two other specimens also showed caseous and catarrhal hepatisation, which condition occurred in seven out of the sixteen cases examined last year. A further point of difference from ordinary catarrhal hepatisation consists in the occasional occurrence of areas of softening in the midst of the hepatised foci, producing rapid excavation; for instance, in the middle of the lower lobe, just as in gangrenous broncho-pneumonia. This result seems to point to the operation of a stronger irritant than that which is usually regarded as the cause of catarrhal pneumonia. Professor Virchow is of opinion that, in some of these cases at least, the inflammatory processes are analogous to those excited in the external parts after injection, which vary in intensity with the individual and the special features of the case.

Another phenomenon has been noted which requires confirmation by thorough clinical observation; it is the outbreak of recent tubercles in these patients. He conld only speak with much reserve on this point, since we bave no fixed data as to the duration of small tubercles-i.e., the submitiary form-and cannot judge positively as to their age. Generally they are regarded as being of recent formation. Clinical observation in certain cases has shown an eruption of tubercles on the laryngeal mucons membrane after injection. Small tubercles have become almost suddenly visible in places which appeared to be perfectly free from them, and they have rapidly given rise to fresh ulcers. It is asserted that this shows the tubereles to have existed prior to the injection, but that they have not been visible. They have been attacked and destroyed by the remedy, and thereby changed into ulcers. Professor Virchow was unable wo controvert this statement as regards the recorded cases, but in his own examination of those parts, which he has always regarded as most suitable for the observation of these recent formations-viz., serous membranes-has revealed the eruption of very recent tubercles under conditions which render it very unlikely that these were of old datc. This is especially seen in the pleura, pericardium, and peritoneum. He bas never been able to confirm the notion that the tubercles were strongly attacked by the remedy and mortified, for in all these cases the submiliary tubercles in question were quite intact, even following injections made some weeks previously. Heace he is the more inclined to the notiun that wheir ernption first took place after the injection.

Owing to the great difficulty in discriminating precisely these very fine forms of tubercle in the lungs themselveg, he would speak only of regions, such as the mucous membrane of the larynx, where miliary tubercles first appeared after injection, or where after more prolonged injections quite recent tubercles have been seen in the membrane. He showed an intestine-procured this month-in which there was a very recent submiliary eruption in the vicinity of old ulcers; the patient, a man forty-one years old, also had recent tubercles in the pericardium. 
In endeavouring to explain these fresh eruptions he remarked that if one admits that every tubercle is due to bacilli, the study of such remote parts as the pericardium deserves special attention. In another case the epicardium had at one spot, not in contacb with the affected part of the lung, a small group of four such miliary tubercles surrounded by marked hyperæmia. There seemed no other explanation than that their germs had come there by metastasis; and why, he asks, should not the metastatic transference of liberated bacilli be deemed a source of more generalised infection? For Professor Koch states that the bacilli resist the action of the remedy, nor indeed are they destroyed, and therefore the possibility must be recognised that the softening process excited by the remedy makes the degenerative products more fluid and more liable to be carried away to create foci elsewhere. This idea is not far fetched, and is linked with anotherviz., the infiltration, under the treatment, of a whole lower lobe into foci of caseous hepatisation, suggesting that material set free from the upper lobe by the destructive processes, and not coughed up, has been sucked into the lung and has excited a kind of caseous "Shluckpneumonia."

Professor Virchow said he felt bound to express these ideas in order to unite with them the warning that still greater caution should be used in operating on cases where the patient has not the strength or the habit of completely coughing up the softened material, and where there is great possibility of the conveyance of this material to other parts of the lung to excite therein fresh foci. Another point on which Professor Koch lays stress as the main effect of his remedy is the destructive process itself. There is no doubt that such an action does take place in many parts ; but it is not quite clear why this mortification does not always occur, as, for instance, in the cases of submiliary tubercles referred to. Professor Virchow admittedas had been described by some earlier observers-in tabercalar pleurisy, for instance, that, especially when the tubercles increased in size, they assume an unusually cloudy, yellowish aspect, and show definite microscopic changes. But at other times. even when injections are continued to the day before death, this change does not occur. Large tubercles may even appear very resistant. They had lately a very remarkable case of a boy three years of age, with tuberculosis of the vertebræ and long bones, and where large tubercles were found in the brain. The injections had reached $0.012 \mathrm{gr}$. It was a surgical case, in which spinal caries with psoas abscess and much disease of the joints and bones of the lower limbs existed. At the necropsy there were as many as seven so-called "solitary tubercles"-i.e, large caseous masses-in the brain and cerebellum; but neither in them nor in their vicinity were any marked changes to be seen. There were a few spots of softening, but not of special import, and certainly none of the nodules showed any marked destruction.

Professor Virchow next drew attention to the conditions observed in cases of phthisis, in ulcers of the intestine and in the ulcers of the respiratory organs, especially in the lungs. As regards the intestine, there could be no question as to the o surrence of mortifying processes similar to those observed in lupus, especially in the older ulcers of wide extent and thickened margins, where there is much fresh submiliary eruption to be seen together with extreme mortification. He showed the specimen from the case which also had pericardial tubercle, in which the destruction of the intestinal ulcer had invaded the serous coat. Had the man survived two days longer perforation must have occnrred. This was so in another case lately related by Professor B Fraenkel where death occurred from perforation. Although such mortification and perforation do take place in tubercular ulceration, yet it was remarkable to have two such instances within two months of severe cases where the mortifying process was in rapid progress. The same is true of ulcers in the organs of respiration, in which very rapid destruction takes place, and the unusually large size of the detached masses must obviate the possibility of their being expectorated, and thereby favour their retention and aspiration with its consequences. Professor Virchow showed also a specimen of very severe laryngeal tuberculosis (from the same case as the pericardial and in testinal specimens referred to) in which twenty injections had been practised, the last on the day preceding death. The specimen showed a recent eruption involving the whole extent of the larynx, of most exceptional severity. Another preparation showed recent caseous hepatisation, from a case in which six injections were made, the last four days before death; another where three injections, the last one week and a half before death, and in which cheesy foci and tracts of diffuse inllammation were present and lastly a preparation obtained that morning show ing a spreading abscess in the lung starting from bron. chiectasis in the lower lobe.

\section{ON CHRONIC DISEASE OF THE UTERINE APPENDAGES ;}

WITH SHORT NOTES OF THIRTY CONSECUTIVE CASES TREATED BY ABDOMINAL SECTION.

By WILLIAM DUNCAN, M D., F.R C.S.ENG., OBSTETRIC PHYSICIAN TO, AND LECTURER ON OBSTETRICS AND GYN ACOLOGY AT, THE MIDDLESEX HOSITTAL.

BEFORE entering on the systematic consideration of the various diseases, I propose to relate briefly the notes of one or two cases out of the thirty on which I performed abdo. minal section, seven of these being in private and twenty. three in hospital practice. For convenience of reference I have arranged all the cases in a tabular form.

CASE 6. Small suppurating and adherent dermoid tumour of right ovary.-Mrs. S - aged twenty-six (an Australian lady), was sent to me by Dr. Cory of ciuildford for chionic pelvic pain and dysmenorrhoea. The patient is a tall, thin, and delicate-looking woman. The catamenia began a sixteen, were regular and normal until four years previously, when she began to suffer pelvic pain, especially on the right side, and radiating throngh to the back; this pain has decidedly increased since her marriage two years ago; she has not been pregnant, and latterly there has been much dyspareunia. On examination nothing is felt abnormal in the lower abdomen. Per vaginam the uterus is not enlarged, but is pushed somewhat to the left side by a rounded, tender, somewhat elastic, and fixed tumour, about the size of an orange, in the right posterior quarter of the pelvis. This was diagnosed as an enlarged ovary, and the patient was kept in bed for two months. Hot iodine douches were used night and morning. Blisters were applied over the right ovarian region, and small doses of corrosive sublimate with iodide of potassium given thrice daily. No improvement resulting, abdominal section was pertormed when the tumour proved to be a suppurating dermoid, with universal adhesions, so that its removal was exceedingly difficult. During the operation some of the purulent contents escaped into the pelvic cavity, and there was oozing from the torn adhesions. The pelvic cavity was flushed with a hot 5 per cent. boracic solution and a glass drainagetube ingerted. The tube was removed in thirty-six hours The patient progressed satisfactorily until a week after the operation, when a small hematocele occurred where the tumour had been. This made the patient's recovery tedious, but I saw her a year after the operation, when she expressed herself as feeling perfectly well in every respect, and she is putting on flesh. At the time of the operation the left tube and ovary had a few adhesions binding them down, but otherwise they appeared healthy; so the adhesions were divided, and the appendage left intact.

CASE 24. Pelvic peritonitis ; right hydro-salpinx, left ovary and tube matted together; cure.-Mrs. $\mathrm{H}$-, aged twenty-seven, married three years; has never been pregnant. Catamenia commenced at fifteen, always more or less painful, worse since marriage. In 1888 she was operated on in Australia for the cure of the dysmenorrhoea, which she was told was due to her womb being bent. She was ill after the operation from "inflammation." On coming to England in 1889 she consulted me. I found " uterus normal in position, but its mobility is impaired. In the left posterior quarter of the pelvis the ovary and tube feel matted together and enlarged ; in the right quarter is a cystic swelling which feels like a dilated tube." On Dec. 7th, 1889, I performed abdominal section, and found the left appendages universally adherent, with much thickening of the tube from chronic salpingitis. The right tube was dilated into a thin-walled cyst, and contained four ounces and a half of serous fluid ; there was

1 Read at a meeting of the Medical Society of London. 